\title{
A Fuzzy AHP based Multi-criteria Decision-making Model to Select a Cloud Service
}

\author{
Hong-Kyu Kwon ${ }^{1}$ and Kwang-Kyu Seo ${ }^{2 *}$ \\ ${ }^{1}$ Department of Industrial \& Management Engineering, Namseoul University, \\ Chonan, Korea \\ ${ }^{2}$ Department of Management Engineering, Sangmyung University, \\ 31, Sangmyungdea-Gil, Dongnam-Gu, Cheonan, Chungnam 330-720, Korea \\ \{hongkyuk@nsu.ac.kr, kwangkyu@smu.ac.kr\}
}

\begin{abstract}
In rapid chaining business environment, information and communication technology (ICT) is a must for the survival of a company and is becoming increasingly important. The emergence of cloud computing represents a fundamental change of ICT services and cloud services continue to grow rapidly with increasing functionality and more users. As a result of this growth, it is a critical issue to select the suitable cloud service provider which meets all the business strategies and the goals of the company. This study presents a fuzzy analytic hierarchy process (AHP) based multi-criter@a decision-making model to choose a suitable cloud service provider for companies' users. In order to achieve this goal, the multiple criteria to select a cloud service provider Were determined and then compared according to their importance. Finally the cloud seryice providens were evaluated to select the best cloud service provider according to the predetermined criteria. In this study, the fuzzy AHP, a fuzzy extension of the multi-criteria decision-making technique AHP, was used to compare these cloud service providers.
\end{abstract}

Keywords: Cloud Service, Infrastnucture as a Service (IaaS), Multi-criteria Decisionmaking Model, Fuzz) AHP

\section{Introduction}

In rapid chaining business environment, information and communication technology (ICT) is a must for the survival of a company and is becoming increasingly important. The emergence of cloud computing represents a fundamental change of ICT services and cloud services continue to grow rapidly. As a result of this growth, the global and Korean major cloud service providers launched commercial B2B and B2C cloud services such as IaaS, $\mathrm{PaaS}$, and SaaS. Cloud services are expected to give an opportunity for enterprises to make new business models. Companies are to deliver a network of virtual services so that companies' users can access them from anywhere in the world without making high capital investment to procure ICT infrastructure, skilled ICT experts and system managers. Thus, they do not invest infrastructure to deploy and operate their services [1,2].

According to increasing companies' users of cloud services, it is a critical issue to select the suitable cloud service provider which meets all the business strategies and the goals of the company. This study presents a fuzzy AHP based multi-criteria decision-making model to choose a suitable cloud service provider focused on the IaaS provider for companies' users. In

\footnotetext{
* Corresponding Author: kwangkyu@smu.ac.kr
} 
order to achieve this goal, the multiple criteria to select a cloud service provider were determined and then compared according to their importance. Finally the candidate IaaS providers as cloud service providers were evaluated to select the best IaaS provider according to the predetermined criteria [1].

Conventional AHP that requires the selection of arbitrary values in pairwise comparison may not be sufficient and uncertainty should be considered in some or all pairwise comparison values [3]. The fuzzy AHP should be more appropriate and effective than conventional AHP in real practice where an uncertain pairwise comparison environment exists. Therefore the fuzzy AHP is used to select best the IaaS provider as a fuzzy extension of the multi-criteria decision-making technique AHP in this study.

\section{Research Background}

This chapter describes the analytic hierarchy process (AHP) and set theory briefly which are basic theories of fuzzy AHP.

\subsection{Analytic Hierarchy Process (AHP)}

An analytic hierarchy process (AHP) was first proposed by Saaty, and je is one of the most commonly used methods for solving multiple-criteria decision-making (MCDM) problems in political, economic, social and management sciences [4]. Using AHP, opinions and evaluations of experts can be integrated, and a complex prôblemcan be devised into a simple hierarchy system with higher levels to lower ones.

The application of AHP to a compley problem involves six essential steps [5, 6]:

(1) Define the unstructured problen and state clearly the objectives and outcomes.

(2) Decompose the complex problem into a herarchical structure with decision elements (criteria and alternatives).

(3) Employ pairwise Comparisons atmong decision elements and form comparison matrices.

(4) Use the eigenvalue method to stimnate the relative weights of decision elements.

(5) Check the consistency property of matrices to ensure the judgments of decision makers are consistent.

(6) Aggregate the relative weights of decision elements to obtain an overall rating for the alternatives.

\subsection{Fuzzy Set Theory}

Fuzzy Set heory is introduced to solve problems involving the absence of sharply defined criteria by Zadeh [7]. If uncertainty (fuzziness) of human decision-making is not taken into account, the results can be misleading. Fuzzy theory is used to solve uncertainty (fuzziness) of human decision-making problems, and it has been applied in a variety of fields.

Fuzzy set theory has evolved in various directions, and one of distinct direction of them is dealing with fuzzy sets as mathematical objects subject to the linguistic method. The underlying logic of linguistic method is that the truth-values are fuzzy sets and the rules of inference are approximate rather than exact [8].

A triangular fuzzy number, a special case of a trapezoidal fuzzy number, is very popular in fuzzy applications. As shown in Figure 1(a), the triangular fuzzy number $\tilde{M}$ is represented by $(a, b, c)$, and the membership function is defined as 


$$
\mu_{\tilde{M}}(x)=\left\{\begin{array}{l}
\frac{x-a}{b-a}, a \leq x \leq b \\
\frac{c-x}{c-b}, b \leq x \leq c \\
0, \quad \text { otherwise }
\end{array}\right.
$$

with $-\infty<a \leq b \leq c<\infty$.

An important concept of fuzzy sets is the $\alpha$-cut. The $\alpha$-cut of a fuzzy number $\tilde{M}$ is the crisp set $\tilde{M}$ that contains all the elements of the universal set $U$ whose membership grades in $\tilde{M}$ are greater than or equal to the specified value of $\alpha$, as shown in Figure 1(b).

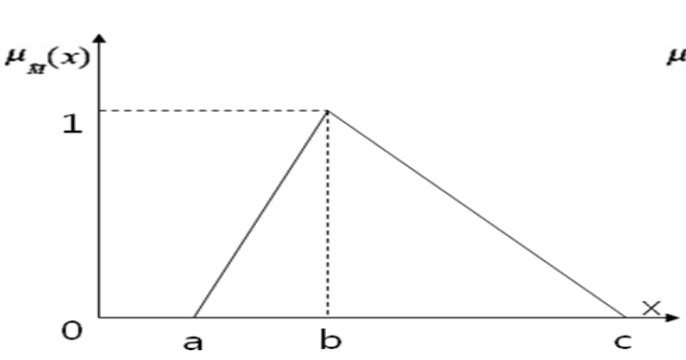

(a)

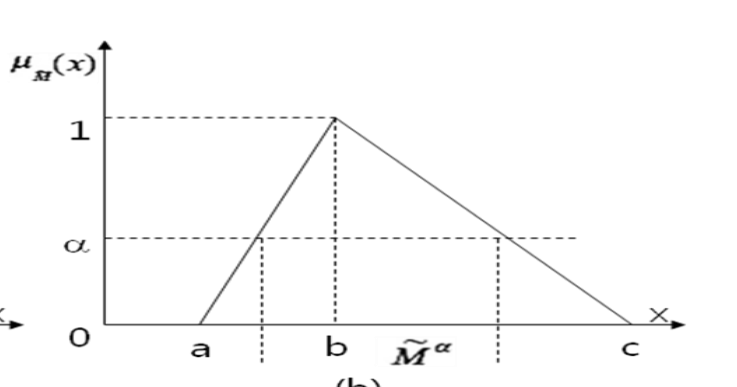

(b)

Figure 1. Triangular Fuzzy Number: (a) Membership Function of a Triangular Fuzzy Number $\tilde{M}=(\boldsymbol{a}, \boldsymbol{b}, \boldsymbol{c})$, (b) $\alpha$-cut of a Trrangular Fuzzy Number $\tilde{M}$

\section{The Proposed Multi-criteria Decision-making Model}

This chapter presents the constuction of herarchy model, the application of fuzzy AHP and the results of the best IaaS provider selection.

\subsection{Construction of a Hierarchy Model}

In the first part of this study, the most important factors for evaluating traditional ICT providers and Ton evaluating cloud service providers, especially IaaS providers, are examined. After a detailed review of the literature and interviews with domain experts, the three criteria such as provider, service and support perspectives and the 8 sub-criteria according to three criteria are identified as shown in Table $1[1,2]$.

\section{Table 1. Criteria for Decision-Making Model}

\begin{tabular}{clll}
\hline \multicolumn{1}{c}{ Criteria } & Provider perspective & Service perspective & Support perspective \\
\hline \multirow{3}{*}{ Sub-criteria } & Service provider's & Service availability & Service Level Agreement \\
& name recognition & Service performance & (SLA) \\
& Service price & Service scalability & Service support \\
& & Service security & \\
\hline
\end{tabular}

The constructed hierarchy model for decision-making is also presents in Figure 2. 


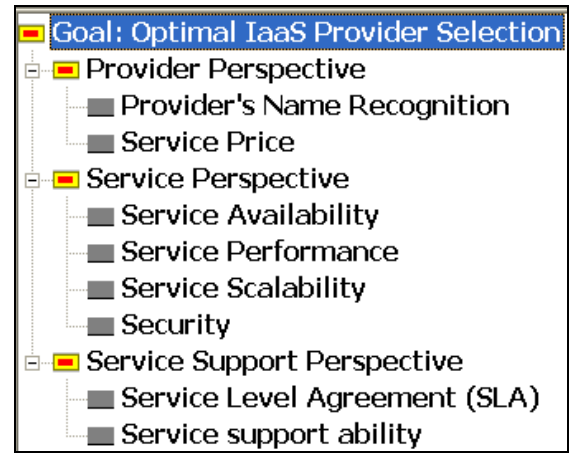

Figure 2. The Constructed Hierarchy Model for Decision-Making

\subsection{Application FAHP and the Result of IaaS Provider Selection}

Fuzzy AHP is used to generate the weighting of the three criteria perspectiyes and the weighting of the performance indicators. Fuzzy AHP has the following six steps [6]:

Step 1: Construct the hierarchical structure with decision elements (e.g., criteria and detailed criteria). Each decision maker is asked to expres relative importance of two decision elements in the same level (e.g., two criteria) by a nine-point scale. Collect the scores of pairwise comparison, and form pairwise companison matrices for each of the $n$ decision makers.

Step 2: Analyze consistency. The pronity of the elements can be compared by the computation of eigenvalues and eigenvectors. The consistency property of the matrix is then checked to ensure the consistency ofjudgments in the pairwise comparison.

Step 3: Construct fuzzy positive matrices. The scores of pairwise comparison are transformed into linguistic yariables, which are represented by positive triangular fuzzy numbers. [9]

Step 4: Calculate the fuzzy weights of decision elements using the Lambda-Max method

Step 5: Integrate the opinions of decision makers. Geometric average is applied to combine the fuzzy weights of decision makers.

Step 6: Obtain final ranking.

To determine the importance of the three criteria and the 8 sub-criteria, a nine-point scale is used in the questionnaires to collect experts' opinions. Fifteen experts are asked to fill out the first questionnaire and they calculate the weight according to their importance.

Nex we-compared the five IaaS providers according to the predetermined importance of crite tia calculated by fuzzy AHP. In this study, we use the expert choice 11.5 [10] to compare and choose the best IaaS provider.

The final results of importance of criteria and sub-criteria and the optimal IaaS provider selection present in Figure 3. 


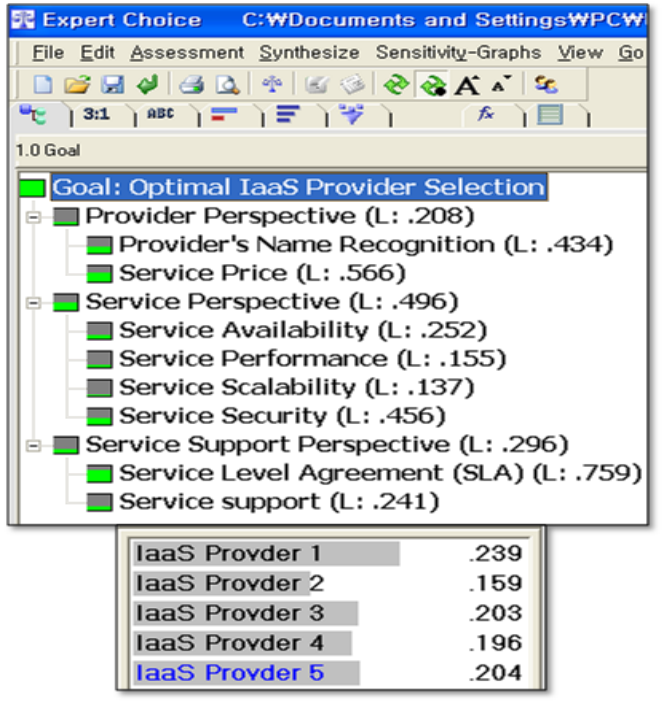

Figure 3. The Final Results of the Best laas Provider Selection

The service perspective $(0.496)$ has the highest weighting. This indicates that providing services to users should be stressed by IaaS selectors of companies. As shown in Figure IaaS provider 1 was selected as the best IaaS provider with 0.239 finally.

\section{Conclusions}

This paper proposed the fuzzy AHP based decision-making model to select a suitable cloud service provider focused on the IaaS provider for companies' users. The three criteria such as provider, service and support perspectives for decision-making were identified and the hierarchy model was aso constructed. And then, the importance of three criteria and 8 sub-criteria were determined by fuzzy AHP.

The results show that service perspective has the highest weighting. This indicates that providing services to users should be stressed by IaaS selectors of companies. The IaaS providers were selected to evaluate for the proposed model. In this study, we compared the five IaaS providers which are-domestic and international providers and serviced in Korean cloud service market The proposed IaaS provider selection methodology was applied successfully.

This study bases on the Fuzzy AHP to propose a systematic decision-making model to provide guidance to IT department managers or CTO regarding performance evaluation and strategies for improving companies performance.

\section{Acknowledgements}

his research was supported by a 2014 Research Grant from Sangmyung University.

\section{References}

[1] H.-K. Kwon and K.-K. Seo, “A Decision-making Model to Choose a Cloud Service using Fuzzy AHP”, Advanced Science and Technology Letters, vol. 35, (2013), pp. 93-96.

[2] S. Lee and K.-K. Seo, "A Decision-making Model for IaaS Provider Selection", Proceedings of the 3rd International Conference on Convergence Technology, (2013), pp. 1217-1218.

[3] C. S. Yu, "A GP-AHP method for solving group decision-making fuzzy AHP problems", Computers and Operations Research, vol. 29, (2002), pp. 1969-2001. 
[4] A. L. Saaty, "The analytic hierarchy process", New York, McGraw-Hill, (1980).

[5] A. H. I. Lee, H. Y. Kang and W. P. Wang, "Analysis of priority mix planning for semiconductor fabrication under uncertainty", International Journal of Advanced Manufacturing Technology, vol. 28, (2006), pp. 351361.

[6] A. H. I. Lee, W.-C. Chen and C.-J. Chang, "A fuzzy AHP and BSC approach for evaluating performance of IT department in the manufacturing industry in Taiwan”, Expert Systems with Applications, vol. 34, (2008), pp. 96-107.

[7] L. A. Zadeh, "Fuzzy sets", Information and Control, vol. 8, (1965), pp. 338-353.

[8] M. M. Gupta, G. N. Saridis and B. R. Gaines, "Fuzzy automata and decision processes", New York, Elsevier North-Holland, (1977).

[9] R. Csutora and J. J. Buckley, "Fuzzy hierarchical analysis: the Lambda-Max method", Fuzzy Sets and Systems, vol. 120, (2001), pp. 181-195.

[10] Expert Choice. Available from: http://www.expertchoice.com.

*Corresponding author: Prof. Kwang-Kyu Seo

Dept. of Management Engineering, Sangmyung University, Korea

E-mail: kwangkyu@smu.ac.kr
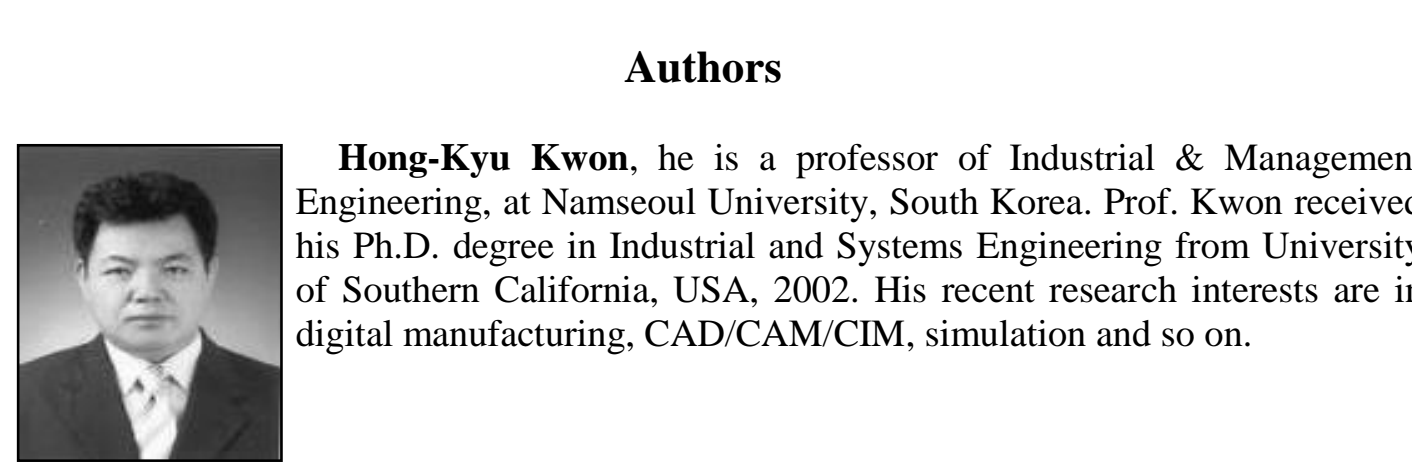

Hong-Kyu Kwon, he is a professor of Industrial \& Management Engineering, at Namseoul University, South Korea. Prof. Kwon received his Ph.D. degree in Industrial and Systerns Engineering from University of Southern California, USA, 2002. His recent research interests are in digital manufacturing, CAD/CAM/CDM, simulation and so on.
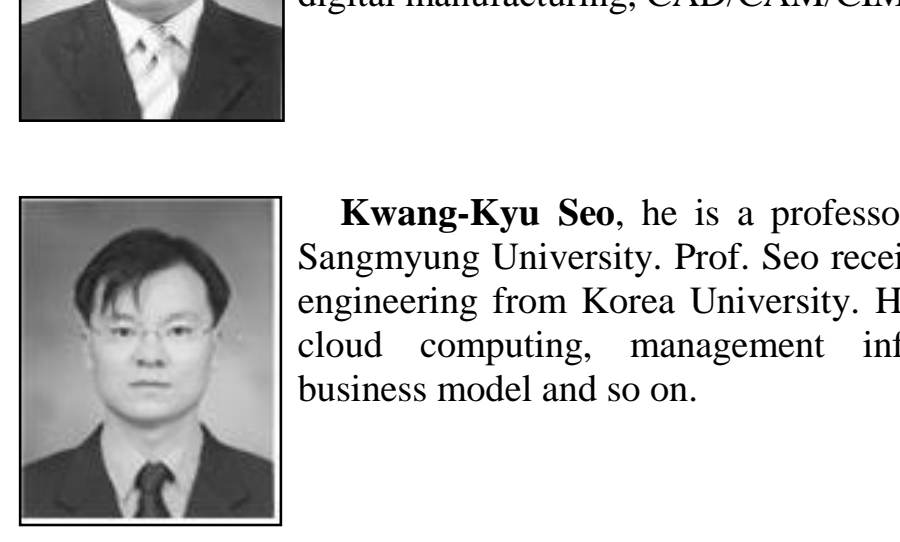

Kwang-Kyu Seo he Is a professor of Management Engineering at Sangmyung University. Prof. Seo received his Ph.D. degree in industrial engineering from Korea University. His recent research interests are in cloud computing, management information system, convergence business model and so on.

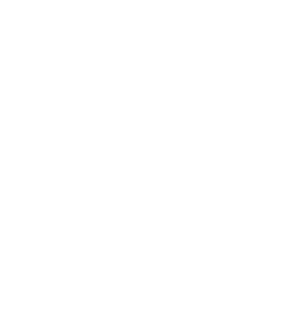

